\title{
Correction: Child sexual abuse among medical school students: experiences and perceptions
}

Alexandra Soldatou - Spiridon I. Pantzios - Maria-Roza Panagiotou - Theodoros Panagiotopoulos • Theodoros Nicoletos $\cdot$ Lina Michala $(1)$

Published online: 7 April 2020

(c) The Author(s), under exclusive licence to Springer Nature Limited 2020

Correction to: International Journal of Impotence Research https://doi.org/10.1038/s41443-020-0254-4

Shortly after publication, the authors noticed a serious typographical error in the opening sentence; namely, that the percentage was stated as $2-5 \%$, whereas it should read $5-25 \%$.

This has been corrected in both the PDF and HTML versions of the Article. 